\section{Commentary: Nothing lasts forever, including valve-sparing root replacement with reimplantation of the aortic valve}

\author{
Christopher Lau, MD, and Leonard N. Girardi, MD
}

Nothing lasts forever and nothing is certain, except for taxes and death. Although there remains no perfect solution for aortic root aneurysms, valve-sparing root replacement (VSRR) with reimplantation of the aortic valve (RAV) offers the potential of a permanent solution to at least some patients without the need for anticoagulation associated with mechanical valve-conduits. In this issue of the Journal, David and colleagues ${ }^{1}$ report an update on the long-term results of RAV with nearly 30 years of long-term follow-up. With 465 consecutive patients and a mean follow-up of $10 \pm 6$ years, the 20-year cumulative incidence of aortic valve reoperations was $6 \%$ and of moderate or severe aortic insufficiency was $10.2 \%$. The results confirm the excellent long-term durability of the preserved native valves.

The report is largely a descriptive series that avoids focusing on detailed analysis of the intricacies and specific repair techniques associated with VSRR that are debated in the literature. However, it shows us the evolution of the technique's application to increasingly complex situations by the Toronto group and the long-term durability of some of these decisions. We see a glimpse of the risk of applying the RAV technique to imperfect cusps requiring leaflet repair and bicuspid aortic valves (BAVs), which was the only variable associated with reoperation in this series. With the authors' admittedly conservative use of RAV with only good leaflets, this series assures us that

From the Department of Cardiothoracic Surgery, Weill Cornell Medicine, New York, NY.

Disclosures: The authors reported no conflicts of interest.

The Journal policy requires editors and reviewers to disclose conflicts of interest and to decline handling or reviewing manuscripts for which they may have a conflict of interest. The editors and reviewers of this article have no conflicts of interest.

Received for publication Aug 17, 2020; revisions received Aug 17, 2020; accepted for publication Aug 18, 2020; available ahead of print Aug 24, 2020.

Address for reprints: Leonard N. Girardi, MD, Department of Cardiothoracic Surgery, Weill Cornell Medicine, 525 East 68th St, M-404, New York, NY 10065 (E-mail: lngirard@med.cornell.edu).

J Thorac Cardiovasc Surg 2021;161:900-1

$0022-5223 / \$ 36.00$

Copyright (C) 2020 by The American Association for Thoracic Surgery

https://doi.org/10.1016/j.jtcvs.2020.08.061

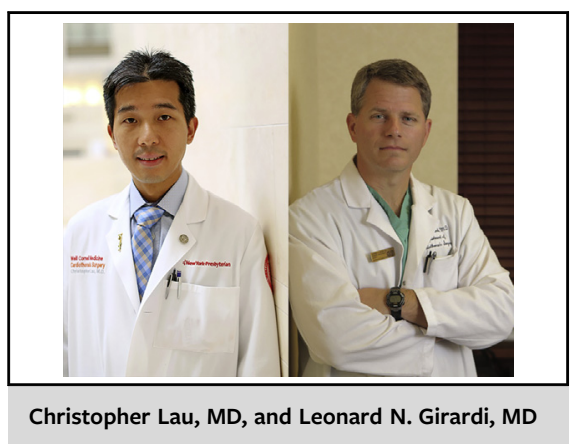

CENTRAL MESSAGE

Valve-sparing root replacement with reimplantation of the aortic valve has excellent long-term durability but patient selection is key.

this very select group will have excellent long-term results. However, the surgical community must continue exploring the frontiers to optimize outcomes in a broader, and potentially greater-risk, population. While most authors comparing the outcomes of VSRR in BAV versus trileaflet valves have found similar mid-term durability, ${ }^{2,3}$ longerterm follow-up is starting to show compromised durability with BAVs. ${ }^{4}$ Similarly, cusp-repair strategies broaden the applicability of VSRR to more patients. While mid-term outcomes of cusp repair are favorable, ${ }^{5,6}$ follow-up beyond 10 years has revealed a divergence in outcomes favoring those not requiring cusp repair. ${ }^{7}$ These and other patient selection factors need further clarification.

The need for analysis of long-term outcomes is further highlighted by the fact that only time since surgery was associated with the development of postoperative aortic insufficiency by multivariable analysis in this series. Furthermore, the cumulative risk of future aortic dissection was $13.8 \%$ at 20 years and was significantly greater in patients with connective tissue disorders. While the operative, short-, and mid-term outcomes of VSRR operations have been highly optimized, further focus is necessary on the future implications of these operations. The effects of creation of neo-sinuses and alterations of laminar blood flow patterns on durability of the aortic valve and downstream aortic events need further investigation. ${ }^{8}$ As the authors highlight, the key to excellent long-term outcomes lies not only in the skill of the surgeon but largely in the selection of the appropriate patients and valves to preserve. The quest to find the patients in whom the preserved aortic valve may last forever continues. 


\section{References}

1. David TE, David CM, Ouzounian M, Feindel CM, Lafreniere-Roula M. A progress report on reimplantation of the aortic valve. $J$ Thorac Cardiovasc Surg. 2021;161:890-9.e1.

2. Kayatta MO, Leshnower BG, McPherson L, Zhang C, Lasanajak Y, Chen EP. Valve sparing root replacement provides similar midterm outcomes in bicuspid and trileaflet valves. Ann Thorac Surg. 2019;107:54-60.

3. Bavaria JE, Desai N, Szeto WY, Komlo C, Rhode T, Wallen T, et al. Valve-sparing root reimplantation and leaflet repair in a bicuspid aortic valve: comparison with the 3-cusp David procedure. J Thorac Cardiovasc Surg. 2015;149(2 suppl):S22-8.

4. Karciauskas D, Mizariene V, Jakuska P, Ereminiene E, Orda P, Ordiene R, et al. Early and long-term results of aortic valve sparing aortic root reimplantation surgery for bicuspid and tricuspid aortic valves. Perfusion. 2019;34:482-9.
5. Lau C, Wingo M, Rahouma M, Ivascu N, Iannacone E, Kamel M, et al Valve-sparing root replacement in patients with bicuspid aortopathy: an analysis of cusp repair strategy and valve durability. J Thorac Cardiovasc Surg. October 24, 2019 [Epub ahead of print].

6. Kari FA, Liang DH, Kvitting J-PE, Stephens EH, Mitchell RS, Fischbein MP, et al Tirone David valve-sparing aortic root replacement and cusp repair for bicuspid aortic valve disease. J Thorac Cardiovasc Surg. 2013;145(3 suppl):35-40.e1.

7. Klotz S, Stock S, Sievers H-H, Diwoky M, Petersen M, Stierle U, et al. Survival and reoperation pattern after 20 years of experience with aortic valve-sparing root replacement in patients with tricuspid and bicuspid valves. J Thorac Cardiovasc Surg. 2018;155:1403-11.e1.

8. Gaudino M, Piatti F, Lau C, Sturla F, Weinsaft JW, Weltert L, et al. Aortic flow after valve sparing root replacement with or without neosinuses reconstruction. J Thorac Cardiovasc Surg. 2019;157:455-65.

\section{Commentary: "Details make perfection, and perfection is not a detail" (Leonardo da Vinci)}

\author{
Stefano Mastrobuoni, MD, MPH, \\ Laurent de Kerchove, MD, PhD, and \\ Gebrine El Khoury, MD
}

In 1995, I (G.E.K.) had the chance to visit during some months Professor Carpentier in Paris and Professor David in Toronto. Both events marked undoubtfully my further professional career; nonetheless, the months spent in Toronto decided my main field of development in cardiac surgery. While reading the last report by David and colleagues $^{1}$ on the reimplantation of the aortic valve (AV), published in the current issue of the Journal, I reflected on the evolution of valve-sparing procedures during these last 25 years, in particular on what is widely

\footnotetext{
From the Cardiovascular and Thoracic Surgery Unit, Saint-Luc's Hospital, Catholic University of Louvain, Brussels, Belgium.

Disclosures: The authors reported no conflicts of interest.

The Journal policy requires editors and reviewers to disclose conflicts of interest and to decline handling or reviewing manuscripts for which they may have a conflict of interest. The editors and reviewers of this article have no conflicts of interest.

Received for publication Aug 18, 2020; revisions received Aug 18, 2020; accepted for publication Aug 18, 2020; available ahead of print Aug 25, 2020.

Address for reprints: Stefano Mastrobuoni, MD, MPH, Cardiovascular and Thoracic Surgery Unit, Saint-Luc's hospital, Catholic University of Louvain, Ave Hippocrate 10, 1200 Brussels, Belgium (E-mail: Stefano.mastrobuoni@uclouvain.be). J Thorac Cardiovasc Surg 2021;161:901-2 $0022-5223 / \$ 36.00$

Copyright (c) 2020 by The American Association for Thoracic Surgery https://doi.org/10.1016/j.jtcvs.2020.08.056
}

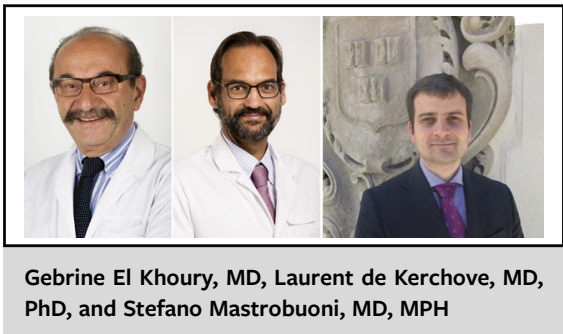

\section{CENTRAL MESSAGE \\ Aortic valve reimplantation pro- \\ vides a comprehensive treat- ment of aortic root dilatation and aortic regurgitation and has shown excellent long-term results.}

known as the David procedure. Also, I could not help but thinking about the development of mitral valve repair during the same time span. David and colleagues have unequivocally shown that reimplantation of the $\mathrm{AV}$ is associated with an excellent survival that is not matched by the best-available valve prosthesis, a low risk of recurrence of severe aortic regurgitation over time, an even lower risk of valve stenosis and, overall, a very low risk of valve reoperation. Further, although initially valve reimplantation was applied to tricuspid AV with little regurgitation, nowadays this procedure is implemented also in bicuspid AV and valves with severe insufficiency. So, although we've come a long way in the last 20 years, why this procedure is still not as widely spread as mitral valve repair? Mitral regurgitation due to dilatation of the annulus (type I) can be simply and effectively treated with 